\title{
ROTAS (TRANS)ATLÂNTICAS NA POE- SIA AFRICANA DO TEMPO COLONIAL: O CASO NOÉMIA DE SOUSA
}

\author{
Simone Pereira Schmidt \\ (Universidade Federal de Santa Catarina)
}

\begin{abstract}
RESUMO
A partir de meados do século XX, os autores africanos marcam sua produção poética com fortes tons libertários. Consolidava-se, na literatura, um discurso de afirmação identitária que desempenhou importante papel na luta anti-colonial. Dentre esses autores, a moçambicana Noémia de Sousa teve seu lugar de importância, e em sua poesia se pode ler o diálogo travado com intelectuais e artistas vinculados, direta ou indiretamente, com as lutas dos negros norte-americanos pelos direitos civis. Este artigo busca interpretar o diálogo estabelecido por Noémia de Sousa, em sua poesia, com os discursos de construção de uma 'identidade negra', especialmente no período de consolidação dos movimentos negros no Ocidente e do crescimento de uma consciência anti-colonial nos países africanos. Na leitura de alguns poemas da autora moçambicana, pretende-se investigar as rotas traçadas por tais discursos, considerando também as questões de gênero implicadas na obra da poetisa.
\end{abstract}

PALAVRAS-CHAVE: Poesia moçambicana; Noémia de Sousa; literatura anti-colonial; raça; gênero.

\section{ABSTRACT}

From the mid-twentieth century, African authors mark their poetry with strong libertarian tones. Their poems can be interpreted as a discourse of identity affirmation that played an important role in anti-colonial struggle. Among these authors, the Mozambican Noemia de Sousa took an important part, and in her poetry we can read a dialogue with intellectuals and artists linked, directly or indirectly, with the struggles of American black movement for civil rights. This article seeks to interpret the dialogue established by Noemia e Sousa, in her poetry, with the construction of a 'black identity' discourse, especially in the consolidation of black movements in West and in the growth of an anti-colonial consciousness in African countries. By reading some Noémia de Sousa poems, we intend to investigate the routes traced by such discourses, also considering the gender issues involved in the poet's work. KEYWORDS: Mozambican poetry; Noémia de Sousa, anti-colonial literature, race, gender. 
Quando Paul Gilroy defende a centralidade da música na cultura do Atlântico Negro, espaço de profundas trocas culturais e identitárias, resultante das rotas diaspóricas dos negros no mundo, parece responder aos versos de Noémia de Sousa que, marcantes, ecoam em nossos ouvidos: “Tirem-nos tudo/mas deixem-nos a música!" (Sousa, 2001: 38).

De fato, o conhecido poema da escritora moçambicana, realizado no calor da hora de um dos mais decisivos momentos de preparação do processo que resultaria na independência das então colônias portuguesas em África, afina-se perfeitamente com a reflexão de Gilroy, assim como de outro conhecido estudioso das questões pós-coloniais, Stuart Hall, para quem a música foi possivelmente o único efetivo patrimônio cultural dos povos da diáspora africana.

O poema, já em seu título, nos remete ao ambiente da escravidão, pois a "Súplica" enunciada dirige-se, pelo que se depreende da leitura dos versos, aos senhores detentores do direito de vida e morte sobre seus escravos. No discurso do eu poético que se dirige a esses senhores, subjaz a tensão que Gilroy identificou como um "terror racial” sempre reafirmado nas expressões culturais afro-atlânticas, como "traços residuais" da "expressão necessariamente dolorosa” da memória escrava (Gilroy, 2001: 158). Nos versos de Noémia, revela-se a presentificação dessa memória, ao lermos as desdobradas súplicas do sujeito lírico: “Tirem-nos a terra em que nascemos; Tirem-nos a luz do sol que nos aquece; tirem-nos a palhota; tirem-nos a machamba; tirem-nos o calor do lume; Podem desterrar-nos, vender-nos como mercadoria, acorrentar-nos à terra (...) Tirem-nos tudo..." (Sousa, 2001: 37)

Mas o que fica patente no poema é o poder reintegrador da música, que por sua ação pode devolver o perdido e o arrancado:

Que onde estiver nossa canção mesmo escravos, senhores seremos;

e mesmo mortos, viveremos,

e no nosso lamento escravo

estará a terra onde nascemos,

a luz do nosso sol,

a lua dos xingombelas,

o calor do lume

a palhota que vivemos,

a machamba que nos dá o pão!

E tudo será novamente nosso, ainda que cadeias nos pés

e azorrague no dorso... (SOUSA, 2001: 38)

Este potencial de construção de um canto paralelo de sobrevivência à dor e à morte, de resistência que anuncia um outro momento histórico encontra-se ainda mais bem elaborado em outro poema de Noémia, este ainda mais simbólico de toda a efervecência cultural e política de que fizeram parte a poetisa e tantos outros intelectuais africanos, que nos anos 50 
davam a largada, mormente a partir do exílio, para o espírito de liberdade que configuraria posteriormente a luta pela independência de seus países. Trata-se do poema "Deixa passar o meu povo" (Sousa, 2001: 57-59), que, em tom algo épico, celebra a chegada de uma consciência transnacional, em consonância com os caminhos que assumiria o tema da negritude no modernismo estético-político afro-americano.

Neste poema, a música está novamente presente, e desta vez desempenhando o papel fundamental de elo de ligação entre as diferentes margens do Atlântico Negro. O eu poético escuta, na morna noite de Moçambique, o chamado de seus irmão norte-afro-americanos, que entoando um spiritual originário do sul dos Estados Unidos, evocam o sofrimento do povo eleito na Bíblia, em seu momento crucial de fuga do cativeiro no Egito, tal como está relatado no Êxodo. "Let my people go", diz o refrão, ecoando nas paredes do Harlem e na "casa de madeira e zinco" em Moçambique. Nesta mesma casa se fundem os "sons longínquos de marimba", vindos não se sabe de onde, talvez da rua em frente, talvez de um passado mítico onde jazem os ancestrais, e a canção no rádio, marca de modernidade, que traz as "vozes da América" para remexer alma e nervos do eu poético.

O spiritual, que chega à casa em Moçambique através das poderosas vozes de Paul Robeson e Marian Anderson, é um ícone fundamental da geração de artistas negros, que, a partir do Harlem, e especialmente nos anos 30, deu corpo a uma intensa produção artística e cultural que ficou conhecida como a Black Renaissance. Música, artes plásticas, literatura, constituíram discursos onde se construiu este novo sujeito negro, fruto de um momento político para o qual confluíram as experiências dos intelectuais negros das Américas, do Caribe e da África. O the new negro movement agregava essas experiências diaspóricas, constituindo, através de seus discursos estéticos e políticos, "um espaço de forte identificação" (Araújo, 2008: 152) com base na história compartilhada da escravidão e da "sua total exclusão da sociedade política moderna" (Gilroy, 2001: 164).

No cerne desse processo de identificação encontrava-se, evidentemente, a experiência racial. Por isso, a poetisa diz: "Dentro de mim soam-me Anderson e Paul /e não são doces vozes de embalo" (Sousa, 2001: 57). Longe de ser acalentada pelo doloroso canto dos músicos afro-americanos, o sujeito poético sente-se provocado por eles, a, "nervosamente", sentar-se à mesa, e escrever.

Ao dizer, em seguida, “E já não sou mais que instrumento / do meu sangue em turbilhão" (idem), o eu lírico parece confirmar uma espécie de "metafísica da substância" do sujeito negro, cuja existência, essencializada, residiria no sangue, e não na experiência compartilhada da história. Nesses versos se explicitam os paradoxos do momento político em que, aglutinados em torno da ideia da raça, os intelectuais afro-americanos, caribenhos e posteriormente, também os africanos, buscavam construir um discurso de afirmação identitária e uma ideologia de libertação. Pois ao celebrar o "sangue em turbilhão" que transforma o sujeito em mero instrumento, a poetisa está, de certo modo, reafirmando uma essencialidade do sujeito negro, que na visão contemporânea, constitui a mais discutível questão daquele forte momento político. 
Sabe-se o quanto tem sido problemática e polêmica a aplicação da categoria "raça" na contemporaneidade. Como conceito totalizante e definidor de identidades, ela precisou ser desconstruída, de modo que, na teorização recente, a "raça" é frequentemente referida entre aspas, como conceito posto "sob rasura", já que nomeia aquilo que, ao ser nomeado, precisa ser, ato contínuo, problematizado e desconstruído.

É importante que se incluam nesta discussão as contribuições advindas da teorização contemporânea, que problematiza - e desconstrói - este conceito. Para Kwame Anthony Appiah, por exemplo, a "raça' é um conceito que incapacita os sujeitos históricos, porque se baseia no pressuposto de alianças estabelecidas "naturalmente" entre eles. $\mathrm{O}$ autor assim resume sua posição: "Em suma, penso ser bastante claro que uma concepção de raça enraizada na biologia é perigosa na prática e enganosa na teoria: a unidade africana e a identidade africana precisam de bases mais seguras do que a raça" (APPIAH, 1997, p. 245).

Em sentido semelhante, Stuart Hall indaga-se "que negro é esse na cultura negra?”. Ao partir desta provocativa indagação, Hall inicialmente entende que o uso do significante "negro" na cultura negra cumpriu papel historicamente importante, já que "nada poderia ter sido feito para intervir no campo dominado da cultura popular mainstream, para tentar conquistar algum espaço lá, sem o uso de estratégias através das quais aquelas dimensões fossem condensadas no significante 'negro"' (HALL, 2003, p. 344). Contudo, o autor acredita que, para a criação de novas estratégias, é necessária a superação deste "momento essencializante". Por "momento essencializante", Hall entende aquele que "naturaliza e des-historiciza a diferença, confunde o que é histórico e cultural com o que é natural, biológico e genético" (p. 345). Através deste processo de des-historicização do significante "negro", tendemos, segundo o autor, a valorizar "pela inversão, a própria base do racismo que estamos tentando desconstruir” (p. 345).

Em outras palavras, o impasse que aqui se coloca diz respeito ao debate em torno daquelas categorias que operam em constante deslizamento entre a afirmatividade política e a negatividade teórica. Dito de outro modo, faz-se necessário reivindicar aquilo que se nega: para as investigações em torno da raça e do racismo, é preciso operar em simultâneo com a reivindicação estratégica da raça, em nome de afirmação de identidade e de direitos sociais, e com a desconstrução de seu significado enquanto eixo aglutinador de significados fixos e essencializantes. Enfim, para além dos problemas do conceito, e do intenso debate que suscita, é necessário que a categoria "raça" continue a ser convocada, para que os problemas em torno dela, de fundo histórico e muito presentes nas sociedades que vivenciaram a experiência do colonialismo, tais como o preconceito racial, a mestiçagem, etc., possam ser discutidos em profundidade. Assim, temas tão difundidos como aqueles ligados ao controverso e problemático conceito de raça, tornam incontornável a sua abordagem. Kwame Anthony Appiah propõe uma provocativa síntese para um impasse dessa natureza, ao afirmar que "como nos lembra Tzvetan Todorov, a existência do racismo não requer a existência de raças; podemos acrescentar que as nações são bem reais, por mais inventadas que sejam suas tradições" (APPIAH, 1997, p. 243). 
Voltando ao poema, é a experiência histórica compartilhada o ponto de ancoragem a partir do qual o sujeito poético, ouvindo as vozes de seus irmãos afro-americanos, Marian e Robenson, apercebe-se da necessidade de rejeitar os modelos impostos pelo colonialismo:
E enquanto me vierem de Harlem
vozes de lamentação
e os meus vultos familiares me visitarem
em longas noites de insónia,
não poderei deixar-me embalar pela música fútil
das valsas de Strauss (Sousa, 2001: 59).

Os versos sinalizam para a construção uma outra história, uma história de resistência e recusa das "premissas estéticas etnocêntricas da modernidade" (Gilroy, 2001, 164), formulando os esboços daquilo que Walter Mignolo viria a chamar um "paradigma outro", ou seja, "o pensamento de um sujeito que não quer que lhe dêem a liberdade, mas que quer tomá-la por si mesmo, construindo seu próprio projeto num paradigma outro, e não [se] não deixar atar ao paradigma da modernidade" (Mignolo, 2003: 31), esgotado em seu potencial desigual de liberação.

Contagiada pelas vozes que vêm do Harlem, e que a vigiam "pelo olho luminoso do rádio", o sujeito poético toma impulso para se debruçar à mesa, e, acompanhada por seus vultos tutelares, cumprir o ofício da escrita: "Todos se vêm debruçar sobre o meu ombro, /enquanto escrevo, noite adiante, / com Marian e Robeson vigiando pelo olho lumínoso do rádio/ — «let my people go» / Oh let my people go" (Sousa, 2001: 59).

Neste momento a distância entre Moçambique e a América se apaga. De seu exílio simbólico de sujeito colonizado, sozinha na noite morna de seu país, a poetisa escreve, e sua escrita é um discurso em contraponto, no sentido atribuído por Edward Said à experiência contrapontística do exilado (Said, 2003: 53), que tem o poder de estar em dois lugares ao mesmo tempo, por meio de uma "consciência de dimensões simultâneas". Assim, o mundo dolorosamente cindido do sujeito colonizado, tal como diagnosticou Fanon (1979: 27-32), se converte, pela música e pela poesia, numa experiência estética libertadora em contraponto: lá e cá, vozes de lamento e revolta se erguem para exclamar "let my peole go", "deixa passar o meu povo".

Dentro da mesma ambiência dos movimento cultural modernista afro-americano, em "A Billie Holiday, cantora", Noémia de Sousa estabelece outro elo, ainda mais íntimo e profundo, desta vez com outra irmã afro-americana, cuja voz sintetiza todos os lamentos dos ex-escravos:

todo o meu povo escravizado sem dó

por esse mundo fora, vivendo no medo, no receio

de tudo e de todos...

O meu povo ajudando a erguer impérios

e a ser excluído na vitória...

A viver, segregado, uma vida inglória, 
de proscrito, de criminoso...

O meu povo transportando para a música, para a poesia, os seus complexos, a sua tristeza inata, a sua insatisfação... (Sousa, 2001: 134)

Mas na dor compartilhada entre as duas mulheres, na escuridão do quarto escuro subitamente povoado pela voz "estranha, profunda, quente, / vazada em solidão" (Sousa, 2001: 134) da cantora negra americana, podemos encontrar mais do que o "fatalismo rácico que faz doer" (idem) anunciado pelo eu poético. Podemos mesmo entrever a difícil conjunção de raça e gênero na trajetória dessas singulares e solitárias mulheres num cenário cultural e político onde a dor da condição dos negros ainda não oferecia espaço para que as particularidades da experiência das mulheres negras fossem percebidas e valoradas.

Vale lembrar que, como afirmaram Maylei Blackwell e Nadine Naber (2002: 191-192), embora as mulheres tenham sido historicamente o grupo mais vulnerável no contexto das formas do colonialismo e de escravidão, ainda assim permaneceram à margem nas políticas masculinistas de liberação nacional e nas lutas comunitárias contra o racismo.

Dentro do ideário que dará corpo e voz ao movimentos de libertação nacional em África, não raro as nações serão representadas e imaginadas como corpos femininos, cuja violação pelos colonizadores requer de seus cidadão e aliados ir em sua defesa. O movimento de libertação surge, assim, como um arranjo entre homens, defendendo a honra e liberdade de suas posses, imaginadas como um corpo feminino familiar (Souza, 1996: 146-147). Por outro lado, segundo Marcos Alves de Souza, a nação é também representada como " mulher casta, submissa e zelosa, filial ou maternal, que "deve casar-se” com o cidadão homem”. Nesta acepção, a “pátria’ é uma virtualidade, representada como a terra natal, à qual estamos ligados por laços afetivos. Poderíamos dizer que a "pátria" é a dimensão feminina e afetiva da nação", e o " papel feminino nesta representação" seria o de "construtoras da nação, já que é das mulheres a tarefa de geração dos cidadãos (homens). Conforme Luiz Tarlei de Aragão, "pureza, renúncia e doação (...) estão intimamente fundidas na categoria 'mãe' (Souza, 1996: 148)”.

O depoimento de Noémia a Michel Laban se insere, embora de maneira pouco crítica, na discussão desse conjunto de ideias. Perguntada sobre a origem da expressão "mãe-África", a escritora responde:

Não sei se veio de algum sítio. Talvez por uma atitude de oposição á África que aparecia nalgumas tentativas de colonos de escrever sobre África, quer dizer que a África surge sempre como uma coisa assim exótica, é sempre uma mulher assim um bocado esquisita, uma coisa selvagem...E eu associo sempre África à ideia de mãe, quer dizer, em contraposição a isso... Muitas vezes, entre os colonos, a conversar, em conversas que ouvia, a mulher africana era equiparada a prostituta, e eles não conheciam profundamente a realidade africana, o que é a mulher africana, o que é uma mãe africana, e eu sei. É um bocado isso (LABAN, 1998: 306). 
Dessa concepção, tão frequente no imaginário anti-colonial, se pode depreender um impasse colocado às mulheres: por um lado, o compartilhamento da luta e o forte pertencimento ao movimento cultural, político, de luta pela transformação das relações étnico-raciais; por outro, a solidão das mulheres nesta luta, e o sentimento de exclusão em momentos decisivos de elaboração identitária, estética e política, da negritude.

Portanto, não é incidental a solidão insistentemente repetida pela voz poética nos versos:

Era de noite e no quarto aprisionado em escuridão apenas o luar entrara, sorrateiramente, e fora derramar-se no chão. Solidão. Solidão. Solidão (Sousa, 2001: 134).

Solidão que só se resolve com a entrada em cena do "arrastado inglês crioulo", na voz melancólica da irmã americana, que com seus blues, cantou a dor de todos os negros, mas, acima de tudo, cantou, tal como o título de seu mais famoso disco sugere - Lady sings the blues -, a grande dificuldade de ser uma mulher negra em seu tempo e lugar.

Para concluir, e tentando unir as pontas dessa breve reflexão, podemos pensar na música, tal como propôs Paul Gilroy, como eixo aglutinador tanto da memória traumática dos "terrores inefáveis da escravidão" (Gilroy, 2001: 158) quanto da experiência vibrante de construção das novas identidades negras nos movimentos culturais e políticos da negritude, da black renaissance norte-americana, seguidos pelos movimentos de libertação na África. Noémia de Sousa percebeu como poucos o alcance e a profundidade do diálogo que então se começava a estabelecer neste que ficou conhecido como o espaço simbólico do Atlântico Negro.

Contudo, dentro dos discursos que anunciavam a unidade de povos dispersos pela diáspora africana no mundo, algumas vozes femininas, ainda solitárias e melancólicas, mas desde então poderosas, levantavam-se para enunciar uma outra música, sonoramente mais polifônica, e perceptivelmente contrapontística, onde os tons da diferença de gênero, para além da igualdade de raça, precisavam ser ouvidos.

\section{REFERÊNCIAS BIBLIOGRÁFICAS}

APPIAH, Kwame Anthony. Na casa de meu pai; a África na filosofia da cultura. Rio de Janeiro; Contraponto, 1997.

ARAÚJO, Maria Manuela Jales Camposana de. Textos afro-americanos e textos africanos: dis-cursos do Eu ao espelho repartido da diáspora discursiva moderna. Universidade de Lisboa-Faculdade de Letras, Doutoramento em Letras, Literatura Norte-Americana, 2008.

BLACKWELL, Maylei e NABER, Nadine. "Interseccionalidade em uma era de globalização: as implicações da conferência mundial contra 
o racismo para as práticas feministas transnacionais". Revista Estudos Feministas, Vol.10, $\mathrm{n}^{\circ}$ 1, 2002 - dossiê sobre a III Conferência Mundial contra o Racismo.

FANON, Frantz. Os condenados da terra. 2.ed. Rio de Janeiro: Civilização Brasileira, 1979.

GILROY, Paul. O Atlântico negro; modernidade e dupla consciência. São Paulo: Ed. 34; Rio de Janeiro: Universidade Cândido Mendes, 2001.

HALL, Stuart. Da diáspora; identidades e mediações culturais. Belo Horizonte: Editora UFMG, 2003.

LABAN, Michel. Moçambique; encontro com escritores. Porto: Fundação Engo António de Almeida, 1998. v.1.

MIGNOLO, Walter. Histórias locais, projetos globais: colonialidade, saberes subalternos e pensamento liminar. Belo Horizonte: Editora UFMG, 2003.

SAID, Edward. Reflexões sobre o exílio e outros ensaios. São Paulo: Companhia das Letras, 2003.

SOUSA, Noémia de. Sangue negro. (MENDONÇA, Fátima; NOA, Francisco; SAÚTE, Nelson, orgs.). Moçambique: Associação dos Escritores Moçambicanos, 2001.

SOUZA, Marcos Alves de. Gênero e raça: a nação construída pelo futebol brasileiro. Cadernos Pagu, Campinas, n. 6-7, 1996, p. 109-152. 